plete, it will be possible to design alloys on a more rational basis and possibly with greater economy of alloys.

After reviewing some of the characteristics of "Brittle Fracture in Mild Steel", which has become so important since the introduction of welding on a large scale into shipbuilding, Mr. T. S. Robertson went on to describe a new form of test for the assessment of brittleness. In this test a shock crack propagated at low temperature passes through material stressed to a value comparable with that carried by the structure in practice. A temperature gradient is maintained along the direction followed by the crack, and this enables the temperature at which the material arrests propagation of the crack to be determined. As the transverse stress is reduced there is a sudden drop in the temperature at which the propagating crack is arrested, and Mr. Robertson suggested that this stress could be regarded as a safe design stress below which there is no chance of brittle fracture at ordinary working temperatures. Mr. Robertson illustrated his remarks with an excellent colour film of a test in progress. This showed that the speed of crack propagation is such that for the usual travel of about six inches, photography at 4,000 frames per second is too slow to record it, since no film so far taken has shown the crack in process of development. The speed of propagation must therefore exceed 2,000 feet per second.

In discussion Prof. J. A. Pope reminded the meeting that engineers are specially interested in the dynamic properties of metals. Under fatigue conditions the nature of the surface is most important: for example, light alloys tested with the as-extruded surface show much poorer properties than when the surface is carefully polished. Again, engineers are interested in machinability. If easily machined alloys are used, it might be possible to use watercooled gas-turbine blades and to maintain a lower metal temperature by taking advantage of the stationary 'air' layer adjacent to the blade surface.

\section{GENETICS AND EMBRYOLOGY}

A

DISCUSSION on the relations between geneties and embryology was held by Section $D$ (Zoology) of the British Association on August 9. In introducing the topic, Prof. C. H. Waddington pointed out that when Bateson invented the word 'genetics' he defined it as the science which dealt with the physiology of descent, a phrase which could be held also to cover the subject which is usually known as experimental embryology. In spite of this, these two branches of biology, both of which have grown extremely rapidly in the past few decades, have developed almost in isolation from one another. After the disproof of at least the simple forms of the theory that differentiation is due to differential nuclear divisions, the concepts commonly used in them gradually diverged. Genetics came to envisage development in terms of the control of single chemical substances or enzymes by nuclear genes; while experimental embryology operated with the notions of gradients, on one hand, and active substances or regions, such as specific plasms or organizers on the other, neither of these types of agent being essentially connected with the nuclei. In quite recent years, these two categories of thought have begun to come together again. Thus, experimental embryology .has been driven to recognize the fundamental importance of developmental competence, and to realize that this property is controlled, at least in the main, by genetical factors; while genetics has discovered that the connexion between gene and final product is not simple, but involves a balance between interacting forces which issues in a condition similar to the competence postulated by the embryologists. It may be hoped therefore that the natural unity between genetics and embryology will come to full expression in the near future.

Dr. R. A. Beatty then discussed some aspects of the importance of chromosomes in development, particularly in mammals. He described the occurrence of polyploids in mice. Triploid embryos are found to occur naturally in certain strains, and both triploids and tetraploids can be induced by hot shocks applied to the early stages of the eggs in the Fallopian tubes. So far no polyploids have been observed after birth; but the embryos appear to develop normally to midterm, and it is hoped that polyploid young will shortly be identified. Turning to a rather different subject, he pointed out that evidence has been gradually accumulating that the cells of differentiated mammalian tissues may contain very different numbers of chromosomes. It does not seem plausible to attribute this to the technical difficulties of counting the chromosomes. There is no evidence that the type of differentiation is correlated with chromosome number; it seems more probable that neighbouring cells can co-operate, so that the important matter is the chromosome balance in the whole tissue rather than in the individual cells composing it.

Dr. D. S. Falconer pointed out that one approach to developmental genetics is to regard a mutation as causing a 'natural experiment'. It may be possible to show that the mutant gene produces some rather simple effect early in development and to trace a whole series of later modifications back to this original cause. As an example of such an approach, he described the analysis of a recent mutation in the mouse known as 'Crinkled'. The main initial effect seems to be the prevention of the formation of hair follicles except during a short period just before birth. This has a direct effect on the coat as a whole, which lacks the long guard hairs, normally initiated at an early period, as well as the short 'zig-zags', which are normally initiated after birth. It also explains the existence of certain localized bald patches, the absence of certain vibrissæ, and, by its effect on the growth of the skin, the distortion of the vertebræe of the tail from which the gene gets its name, as well as a number of other minor effects.

After the discussion, a series of cinema films were shown, one of which demonstrated the technique used for inducing polyploidy in mouse eggs.

\section{SHIPBUILDING}

A $\mathrm{N}$ international conference of naval architects $\mathrm{A}$ and marine engineers was held during June 25-30, with proceedings in London, Glasgow and Newcastle upon Tyne.

The first paper read in London, "Ships Structures -A Century of Progress", by Mr. R. B. Shepheard, of Lloyd's Register of Shipping, traced the development of ships' structures from the wooden ships in general use one hundred years ago, through the stages of iron and riveted mild steel to the modern 